Systolic and diastolic arterial blood pressure by standard occupational group at baseline and four years' follow up of healthy, untreated elderly people (mean age at baseline 74.4 years, mean education 11.2 years) compared with those with incident disease (mean age at baseline 75.8 years, mean education 10.9 years) or hypertension only (mean age at baseline 75.6 years, mean education 10.6 years). Values are mean (SD) unless stated otherwise

\begin{tabular}{|c|c|c|c|c|c|}
\hline \multirow[b]{2}{*}{ Group } & \multirow{2}{*}{$\begin{array}{c}\text { No of } \\
\text { patients }\end{array}$} & \multicolumn{2}{|c|}{ Baseline blood pressure $(\mathrm{mm} \mathrm{Hg})$} & \multicolumn{2}{|c|}{ Follow up blood pressure $(\mathrm{mm} \mathrm{Hg})$} \\
\hline & & Systolic & Diastolic & Systolic & Diastolic \\
\hline Unclassified & 8 & $171(21)$ & $92(4)$ & $164(19)$ & $92(10)$ \\
\hline 1 & 34 & 155 (19) & $83(10)$ & $162(21)$ & $89(10)$ \\
\hline 2 & 31 & $152(26)$ & $82(11)$ & $157(24)$ & $83(9)$ \\
\hline 3 & 14 & $139(13)$ & $82(9)$ & $150(17)$ & $86(11)$ \\
\hline 4 & 40 & $148(20)$ & $84(10)$ & $160(22)$ & $87(8)$ \\
\hline 5 & 15 & $157(12)$ & $85(6)$ & $163(17)$ & $88(10)$ \\
\hline 6 & 8 & $156(14)$ & $83(7)$ & $159(12)$ & $91(6)$ \\
\hline 7 & 26 & $159(24)$ & $82(8)$ & $164(20)$ & $86(11)$ \\
\hline 8 & 6 & $138(23)$ & $83(11)$ & $137(10)$ & $80(4)$ \\
\hline 9 & 11 & $157(24)$ & $88(11)$ & $156(18)$ & $88(11)$ \\
\hline Healthy & 195 & $153(22)$ & $84(9)$ & $159(20)$ & $87(10)$ \\
\hline Diseased & 163 & $160(23)$ & $85(10)$ & $159(22)$ & $86(11)$ \\
\hline Hypertension only & 29 & $181(18)$ & 96 (12) & $169(18)$ & $90(10)$ \\
\hline
\end{tabular}

\section{Comment}

In the elderly, changes in blood pressure relate to health. In those who remained healthy blood pressure continued to rise by $1.5 \mathrm{~mm} \mathrm{Hg}$ per year but fell in those who developed disease (representing probable heterogeneous effects of different medical conditions). In the healthy group no rise was seen in retired blue collar workers. Possibly, retired manual workers have more unrecognised disease, consistent with a persistent effect of socioeconomic factors on health status in old age. For healthy individuals the most important predictor of blood pressure at follow up was baseline blood pressure, accounting for $24 \%$ of the variance of systolic, but only $6 \%$ of the variance of diastolic, pressure. In general, disease affected systolic more than diastolic pressure. Hence the poorer correlation between baseline and follow up diastolic pressure compared with systolic pressure is not easily explained by possible undetected disease in the healthy group and deserves further investigation.

We thank the patients and general practitioners.

Contributors: JMS designed and supervised the study, collected and analysed the data, interpreted the results, and reported the findings; he will act as guarantor for the paper. WJMacL and IJD designed and supervised the study, interpreted the results, and reported the findings. SI and SC collected the data, interpreted the results, and reported the findings.

Funding: This study was supported by a grant from the chief scientist's office, Scotland.

Conflict of interest: None

1 Starr JM, Bulpitt CJ. Hypertension. In: Ebrahim S, ed. Epidemiology of old age. London: BMJ publications, 1996.

2 Landahl S, Bengtsson C, Sigurdsson JA, Svanborg A, Svardsudd K. Agerelated changes in blood pressure. Hypertension 1986;8:1044-9.

3 Bush TL, Linkens R, Maggi S, Hale WE. Blood pressure changes with ageing: evidence for a cohort effect. Ageing 1989;1:39-45.

Starr JM, Deary IJ, Inch S, Cross S, MacLennan WJ. Age-associated cognitive decline in healthy old people. Age Ageing 1997;26:295-300.

5 Office of Population Censuses and Surveys. Standard occupational classifcation. London: HMSO, 1991.

(Accepted 26 March 1998)

\title{
Short stature and Helicobacter pylori infection in Italian children: prospective multicentre hospital based case-control study
}

Clinica Pediatrica, Università di Torino, 28100 Novara, Italy Giuseppina Oderda, researcher

Elena Chiorboli, fellow in paediatrics G Bona, associate professor

Unità Operativo Epidemiologia, Centro per lo Studio e la Prevenzione Oncologica,

Azienda

Ospedaliera

Careggi, 50131

Florence, Italy

D Palli,

medical epidemiologist C Saieva,

fellow in public health

Correspondence to: Dr Oderda oderda@med. no.unipmn.it

Members of the study group are listed at the end of the article

BMJ 1998;317:514-5

\author{
Giuseppina Oderda, D Palli, C Saieva, Elena Chiorboli, G Bona on behalf of the Italian Study Group \\ on Short Stature and $H$ pylori
}

Helicobacter pylori is mainly acquired in childhood, ${ }^{1}$ but the diseases associated with such infection remain unknown. Scottish and Italian schoolchildren infected with $H$ pylori showed reduced growth in height, ${ }^{23}$ and $H$ pylori gastritis was found in $55 \%$ of French children examined for short stature. ${ }^{4}$ To evaluate the role of $H$ pylori and socioeconomic factors on growth we compared children with idiopathic short stature with those of normal height.

\section{Subjects, methods, and results}

This study was approved by and conducted within the guidelines of the gastric disease section of the Italian Society for Paediatric Gastroenterology and Hepatology (SIGEP). Between April 1996 and March 1997 we recruited 134 consecutive children aged 5-13 years (median 9.8 years) whose height was below the third centile-that is, two standard deviations below the mean height of their peers-from 26 paediatric gastroenterology and endocrinology units in Italy. We individually matched them with children of the same age and sex from the same region whose height was above the 25th centile and who had been referred for minor diseases. Obvious medical reasons for short stature (chronic or neoplastic disease with or without genetic abnormalities) were excluded by history and appropriate tests. Information on risk factors was collected by structured questionnaires with questions on socioeconomic status (education, number of cohabiting relatives, and number of rooms at home) and anthropometric data. Weight and height were measured and serum samples collected.

Serum was tested for $H$ pylori IgG in a central laboratory by enzyme linked immunosorbent assay (ELISA) (Helori, Eurospital, Italy). The assay was concurrently validated in 127 children of similar age whose $H$ pylori status was known from the results of gastric biopsy. Children were considered to be infected when their titre was $>12 \mathrm{AU} / \mathrm{ml}$, the cut off point determined from receiver operating characteristic curves (sensitivity $87 \%$, specificity $94 \%$ ). The Wilcoxon rank sum test was used to evaluate differences in continuous variables. Categorical data analysis was used on matched sets. Conditional logistic regression models were used for multivariate matched analyses. 
Cases had a lower birth weight $(\mathrm{P}<0.01)$ and their parents were shorter $(\mathrm{P}<0.01)$ and had attended school for fewer years $(\mathrm{P}<0.01)$ (table). Families of controls had fewer children but the same number of rooms at home. A high crowding index and presence of more than one type of pet was significantly associated with short stature (table). Serology showed $H$ pylori infection in 27 cases $(20 \%)$ and 18 controls $(13 \%)(\mathrm{P}=0.191)$. Prevalence tended to be higher in boys, but the difference was significant only in cases $(27 \%(23 / 85)$ in short boys $v 10 \%(5 / 49)$ in short girls, $\mathrm{P}=0.03)$ and tended to be higher in cases with lower growth hormone concentrations $(22 \%(10 / 46)$ in those with peak hormone concentrations $<10 \mathrm{pg} / \mathrm{l} v$ $12 \%(6 / 50)$ in those with concentrations $\geqslant 10 \mathrm{pg} / \mathrm{l}$; $\mathrm{P}=0.314$ ). Parental height, lower birth weight, and a crowded home persisted in a multivariate analysis as independent predictors of short stature.

\section{Comment}

Our results show that $H$ pylori is not a risk factor for short stature and that reduced growth is related to genetic determinants such as parental height and to mixed genetic and environmental factors such as birth weight. Low socioeconomic status was relevant. The decreased growth found in Scottish and Italian schoolchildren infected with $H$ pylori might be related to the association between lower socioeconomic group and $H$ pylori acquisition. ${ }^{23}$ The higher prevalence of $H$ pylori in disadvantaged children suggests that infection should be considered a marker of low socioeconomic group in studies on growth, with other factors causing the reduced growth. Although genetic factors cannot be modified, more attention should be paid to pregnancy, living conditions, nutrition, infections, and emotional deprivation. The association between short stature and low socioeconomic group seems particularly relevant in view of the reported unsatisfactory long term efficacy of expensive treatment with growth hormone. ${ }^{5}$

Members of the study group were M Baldassarre (Bari), V Benigno (Palermo), E Braggion (Palermo), A Carlucci (Lanciano), G L de'Angelis (Parma), F De Luca (Messina), T Gentile (I'Aquila), G Guariso (Padua), L Iughetti (Florence), G Lauriola (Manfredonia), P Lionetti (Florence), A Liotta (Palermo), F Lizzoli (Pavia), R Longhi (Como), V Lucidi (Rome), A Masciale (Bitonto), M Pastore (San Giovanni Rotondo), A Pavanello (Pordenone), F Rea (Naples), C Romano (Messina), P Roggero (Milan), V Rutigliano (Bari), S Salardi (Bologna), M S Scotta (Varese), M Spina (Catania), A Tozzi (Naples).

We thank Eurospital (Trieste, Italy) for providing free serological testing.

Contributors: GO designed and coordinated the study and wrote the manuscript. DP contributed to the epidemiological aspect of the study design, was responsible for the statistical analysis, and contributed to writing the manuscript. CS was jointly responsible for statistical analysis and interpreting data and revised the final version of the manuscript. EC supervised the collection of clinical data and critically revised the manuscript. GB was jointly responsible for the original study proposal and for coordination. The members of the study group approved the study proposal after extensive discussion, recruited all cases and controls at the 26 participating centres, completed the questionnaires, and collected blood for antibody determination. They also agreed to the adding of their names to the manuscript as members of the study group to show where the recruitment centres were. All approved the final version of the manuscript that was submitted for publication. GO and DP are guarantors for the study.

Funding: None

Conflict of interest: None.
Distribution of 134 cases and 134 controls according to selected characteristics and by matched sets

\begin{tabular}{|c|c|c|c|c|}
\hline & No & & & Odds ratio ( \\
\hline or & & controls & sets ${ }^{*}$ & Univariate† \\
\hline
\end{tabular}

\begin{tabular}{lrrrrrr}
\hline Positive & 27 & 18 & 225 & & \\
\hline Negative & 107 & 116 & 1691 & $1.6(0.8$ to 2.9$)$ & $0.8(0.3$ to 2.2$)$ & 1.3 (0.5 to 3.3) \\
\hline Father's height $(\mathrm{cm}):$
\end{tabular}

Father's height $(\mathrm{cm})$ :

\begin{tabular}{lrrrrr}
\hline$<165$ & 54 & 7 & 351 & & \\
\hline$\geqslant 165$ & 80 & 127 & 476 & $12.7(4.6$ to 35.3$)$ & $8.7(2.8$ to 27.6$)$ \\
\hline \multicolumn{2}{l}{ Mother's height $(\mathrm{cm}):$} & & & & \\
\hline$<155$ & 69 & 13 & 762 & & \\
\hline$\geqslant 155$ & 65 & 121 & 659 & $10.3(4.5$ to 23.9$)$ & $8.0(3.0$ to 20.9$)$ \\
\hline
\end{tabular}

Mean parental height $(\mathrm{cm})$ :

\begin{tabular}{lrrrrr}
\hline$<160$ & 62 & 5 & 260 & & \\
\hline$\geqslant 160$ & 72 & 129 & 369 & $20.0(6.3$ to 63.8$)$ & 28.6 (7.3 to 112) \\
\hline Parents' education (years): & & &
\end{tabular}

Parents' education (years):

\begin{tabular}{|c|c|c|c|c|c|c|}
\hline$<12$ & 28 & 11 & 523 & & & \\
\hline$\geqslant 12$ & 106 & 123 & 6100 & $3.8(1.6$ to 9.4$)$ & 2.1 (0.9 to 6.4$)$ & \\
\hline \multicolumn{7}{|c|}{ Birth weight $(\mathrm{g})$ : } \\
\hline$<2850$ & 38 & 17 & 731 & & & \\
\hline$\geqslant 2850$ & 96 & 117 & 1086 & 3.1 (1.5 to 6.3$)$ & & 9.6 (2.4 to 37.9$)$ \\
\hline \multicolumn{7}{|c|}{ Crowding index (subjects/room): } \\
\hline$\geqslant 1$ & 17 & 7 & 215 & & & \\
\hline$<1$ & 117 & 127 & 5112 & $3.0(1.1$ to 8.2$)$ & & $6.9(1.0$ to 48.7$)$ \\
\hline \multicolumn{7}{|c|}{ Pets (No of types): } \\
\hline$>1$ & 24 & 7 & 123 & & & \\
\hline $0-1$ & 110 & 127 & 6104 & 3.8 (1.6 to 9.4$)$ & 1.9 (0.6 to 5.9$)$ & \\
\hline
\end{tabular}

*Distribution of matched sets according to combination of exposure status (positive or negative) for each case and control.

†McNemar's test based on matched sets.

$\ddagger$ Conditional logistic regression model including terms for $H$ pylori, father's height, mother's height, parental education, and presence of pets.

$\S$ Conditional logistic regression model including terms for $\mathrm{H}$ pylori, mean parental height, birth weight, and crowding index.

1 Banatvala N, Mayo K, Megraud F, Jennings R, Deeks JJ, Feldman RA. The cohort effect and Helicobacter pylori. J Infect Dis 1993;168:219-21.

2 Patel P, Mendall MA, Khulusi S, Northfiel TC, Strachan DP. Helicobacter pylori infection in childhood: risk factors and effect on growth. BMJ 1994;309:1119-23.

3 Raymond J, Bergeret M, Benhamou PH, Mensah K, Dupont C. A 2 year study of Helicobacter pylori in children. J Clin Microbiol 1994;32:461-3.

4 Perri F, Pastore M, Leandro G, Clemente R, Ghoos Y, Peeters M, et al Helicobacter pylori infection and growth delay in older children. Arch Dis Child 1997:77;46-9.

5 Coste J, Letrait M, Carel JC, Tresca JP, Chatelain P, Rochiccioli P, et al. Long term results of growth hormone treatment in France in children of short stature: population, register based study. BMJ 1997;315:708-13.

(Accepted 19 February 1998)

\section{Correction}

Seasonal variation in coronary artery disease mortality in Hawaii: observational study

An authors' error occurred in this paper by Todd B Seto and colleagues (27 June, p 1946-7). The graph of variation in average temperature was incorrect. The correct graph is shown below. Red lines represent monthly averages and blue lines three month moving averages.

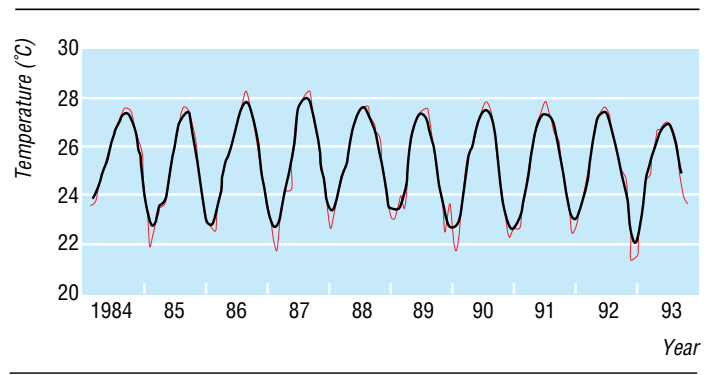

